\title{
TRANSFERINDO PRÁTICAS: CONSTRUINDO CONHECIMENTO ARQUITETURAL LOCALMENTE
}

RESUMO

0 artigo traz um estudo qualitativo dos processos organizacionais que deram suporte à transferência de conhecimento para uma nova fábrica, detalhando os maiores desafios que a organização teve de enfrentar durante seu primeiro ano de operações. Apesar do sucesso obtido na transferência de conhecimento individual para cada área em separado, a empresa enfrentou muitos desafios em sua aplicação, uma vez que não tinha desenvolvido o conhecimento arquitetural - relativo à junção e aplicação das várias bases individuais de conhecimento. Conhecimento este que teve de ser desenvolvido localmente por meio de mecanismos de experiência, negociação e sensemaking. 0 estudo ressal ta a importância do conhecimento arquitetural, uma dimensão até agora não considerada nos estudos de transferência de conhecimento.

\section{Paulo Prochno}

Ibmec

\begin{abstract}
The paper brings a qualitative study on the organizational processes supporting knowledge transfer to a new automotive plant, detailing the major challenges that the organization had to face during its first year of operations. Although the company was quite successful at transferring component knowledge to each area individually, it faced many challenges in the application of this knowledge, because architectural knowledge was missing. This architectural knowledge had to be devel oped locally, through mechanisms of experience, negotiation and sensemaking. The case sheds new light into architectural knowledge, which is an important dimension in knowledge transfer to new settings that has not been considered in knowledge transfer studies.
\end{abstract}

PALAVRAS-CHAVE Transferência de conhecimento, aprendizado, América Latina, rotinas organizacionais, competências organizacionais. KEY WORDS Knowledge transfer, learning, Latin America, organizational routines, organizational competences. 


\section{INTRODUÇÃO}

Ao global izar suas atividades, as empresas precisam transferir conhecimento e práticas entre suas diversas subsidiárias espal hadas pelo mundo. A transferência de conhecimento tem sido considerada uma importante fonte de vantagem competitiva (W inter eSzulanski, 2001), mas ao mesmo tempo traz muitos desafios às organizações. Barreiras diferentes podem surgir no processo de transferência, especialmente quando o ambiente do receptor é consideravel mente diferente do da fonte. É o caso, por exemplo, do estabelecimento, pelas empresas, de "meIhores práticas" em todas as suas subsidiárias no mundo, ou quando são abertas novas unidades em países muito distantes do país de origem da empresa.

Este artigo traz um estudo qualitativo sobre os processos organizacionais que dão suporte à transferência de conhecimento em uma nova fábrica de automóveis, detalhando os maiores desafios pelos quais a organização teve de passar durante seu primeiro ano de operações. Trata-se da primeira fábrica que a montadora instalava no país, portanto a transferência de conhecimento era essencial para o sucesso desse novo cenário.

Embora a empresa tivesse sido bem-sucedida na transferência de conhecimento dos componentes em cada área separadamente, ela enfrentou muitos desafios na aplicação desse conhecimento, uma vez que 0 conhecimento arquitetural estava faltando. Conhecimento do componente foi originalmente definido no contexto de desenvolvimento de produtos como "o conhecimento sobre cada conceito essencial de projeto e a maneira como el e é implementado em cada módulo em particular", e conhecimento arquitetural como "o conhecimento sobre as formas com as quais os componentes são integrados e ligados de maneira coerente" (Henderson e Clark, 1990). Por exemplo, no caso de um ventilador doméstico, o conhecimento do componente está rel acionado a cada sistema separado que o compõe: 0 motor, as pás, o sistema de controle, a grade de proteção; e o conhecimento arquitetural está relacionado a como os diferentes componentes irão funcionar em conjunto (Henderson e Clark, 1990). Esses são os dois diferentes tipos de conhecimento que devem estar presentes quando se deseja montar um ventilador doméstico. A mesma situação pode ser aplicada à gestão da maioria dos produtos e serviços que conhecemos: cada sistema pode ser separado em diferentes componentes, e tanto o conhecimento sobre eles quanto como o conhecimento de como juntá-los são necessários para operar e gerir o sistema.
Essa mesma lógica pode ser aplicada no projeto de produtos para compreender as dimensões do conhecimento organizacional como um todo. $\mathrm{Na}$ indústria pesquisada, o conhecimento arquitetural teve de ser desenvolvido localmente, por meio da experiência, da negociação e da construção de sentido sensemaking. 0 presente caso sugere que o conhecimento arquitetural é a dimensão mais importante na transferência de conhecimento para novos ambientes, permitindo a aplicação dos diversos elementos do conhecimento dos componentes desenvolvido em cada área. Mais importante, o desenvolvimento local de conhecimento arquitetural permitiu um maior entendimento entre os trabalhadores locais sobre sobre os sistemas de gestão e produção da matriz.

Algumas implicações são discutidas. Primeiro, quando do planejamento da transferência de conhecimento e práticas, os gestores devem concentrar mais esforços na transferência de conhecimento arquitetural, uma vez que se trata do mais importante e desafiador elemento. A transferência dos sistemas de atividades como um todo de uma única localização - em oposição à transferência de atividades individuais de diferentes localizações - é uma forma de responder a esse desafio. Porém, o conhecimento arquitetural também deveria ser desenvolvido em parte localmente, uma vez que engloba as relações locais no ambiente para o qual está sendo transferido. Do lado acadêmico, pesquisadores precisam ir além do foco usual na transferência de conhecimento do componente e pesquisar os desafios proporcionados pela interdepen dência de diferentes grupos de conhecimento, bem como o modo como estes últimos afetam o processo de transferência.

\section{REVISÃO DA LITERATURA}

0 estudo de transferência de práticas organizacionais tem sido um tópico importante na pesquisa em Administração nos últimos anos. Isso ocorreu em função de fenômenos como o aumento da importância de redes organizacionais, a expansão geográfica das empresas e o uso disseminado do benchmarking como uma forma de meIhorar o desempenho. Pela transferência de práticas as empresas podem ganhar com as sinergias e a maximização do desempenho em suas diversas unidades, assegurando consistência e tornando-se capazes de el evar suas práticas baseadas naquilo que elas - ou outras empresas - fazem melhor (O'dell e Grayson Jr., 1998; Argote, 1999). Existem diferentes abordagens para se estudar a transferência de práticas entre e intra-empresas, de um estudo 
individual focado em uma única organização (Brannen et al., 1998; Fruin, 1998) até estudos de grande escala (Galbraith, 1990; Szulanski, 1996).

Dentre as várias correntes de pesquisa, uma investiga se ocorreu ou não transferência de conhecimento ea que velocidade. Entre empresas, por exemplo, Epple et al. (1996) descobriram que a transferência acontece de forma bastante rápida quando uma nova mudança é introduzida em uma fábrica. Henderson e Cockburn (1996) encontraram evidência de disseminação de conhecimento entre programas de pesquisa relacionados dentro da mesma empresa. Conhecimento e práticas também são transferidos entre empresas na mesma cadeia (Darr et al., 1995; Baum e Ingram, 1998) ou mesmo entre organizações (Zimmerman, 1982). Adotando uma perspectiva diferente, autores da tradição neo-institucionalista anal isaram a difusão das práticas entre organizações (Tolbert e Zucker, 1983; Fligstein, 1985), focando as forças miméticas e normativas que causam a adoção de certas práticas nas organizações de modo que estas alcancem legitimidade.

Inspirados pelos trabalhos de difusão de inovação ver Rogers (1995) para uma revisão do tema - e desenvolvimento teórico de aprendizagem organizacional, conhecimento e rotinas, alguns pesquisadores começaram a olhar o fenômeno em maior detalhe. Ao invés de procurar por evidências sobre haver ou não transferência de conhecimento, esses estudos procuravam as contingências que influenciaram a velocidade ea dimensão da transferência do conhecimento. 0 primeiro grande esforço para anal isar sistematicamente as barreiras para a transferência de práticas foi o estudo de Szulanski (1996) sobre aderência interna. Baseado em um grupo de 112 melhores práticas de transferências em oito organizações, 0 autor testou uma série de fatores que poderiam ter levado à aderência - definida como a dificuldade de transferência de conhecimento intra-organizacional. 0 autor desenvolveu, ainda, medidas para quatro grupos de fatores que tendem a influenciar a dificuldade da transferência de conhecimento: as características do conhecimento transferido, da fonte, do receptor e do contexto em que a transferência ocorreu. Os resultados sugerem que as três mais importantes origens para a aderência são: a falta de capacidade de absorção do receptor, a ambigüidade causal e a dificuldade de relação entre a fonte e 0 receptor. A capacidade de absorção é definida por Cohen e Levinthal (1990) como a habilidade da empresa em reconhecer o valor de informações externas, assimilá-las e aplicá-las. Embora eles não usem esse conceito em específico, outros autores encontraram resultados seme-
Ihantes aos de Szulanski: muitos problemas surgem quando a organização receptora não tem compreensão do que está sendo transferido (Rothwell, 1978) e experiências anteriores com a tecnologia na organização receptora minimizam as perdas de produtividade na transferência (Galbraith, 1990).

Estudos sobre a transferência de práticas são cada vez mais focados em como superar as barreiras às transferências, sugerindo maneiras de as organizações pesquisadas aumentarem a efetividade de suas transferências. Estas podem ocorrer pela mudança de pessoal, de tecnologia ou de estrutura, ou pela modificação do perfil das pessoas - por exemplo, por meio de treinamento -, da tecnologia ou da estrutura da organização receptora (Argote, 1999). Zander e Kogut (1995) descobriram que o conhecimento que é codificado em documentos e pode ser facilmente ensinado resulta em transferências mais rápidas; Epple et al. (1996) sugerem que uma maneira efetiva de transferir conhecimento é "embuti-lo" em tecnologia. Adler e Cole (1993), por sua vez, mostraram como padronização e documentação detal hadas das atividades resultam em transferência efetiva de conhecimento. Já Winter e Szulanski (2001) sugerem que as empresas devem desenvolver ao longo do tempo um "núcleo central", definido como o fornecedor ideal de informações para um replicador de um modelo particular de negócios. Esse núcleo especifica quais partes são replicáveis, quais atributos são criados e as características do ambiente em que vale a pena replicá-los. Isso pode ser visto como um mecanismo de transferência de ordem maior, um que codifique todo o conhecimento necessário para que a transferência de um determinado grupo de práticas tenha sucesso. Todos esses estudos sugerem atenção especial para os mecanismos de transferência, que devem reduzir a ambigüidade causal das práticas.

Embora tenha sido feito um grande progresso nas questões relacionadas aos mecanismos de transferência, preocupações específicas relacionadas ao processo de transferência permanecem subexploradas. 0 foco das pesquisas tem sido as empresas-fonte de conhecimento e as fases de iniciação e implementação. Organizações receptoras e processos de aplicação inicial de conhecimento e sua integração, ainda não foram estudados em detalhe. A notável exceção é uma série de estudos focada na transferência dos sistemas japoneses de gestão para os Estados Unidos (Liker et al., 1998). Dado o tom internacional dessa linha de pesquisa, os autores prestam mais atenção às diferenças culturais e às fases de aplicação inicial de conhecimento e sua integração, focando em características que permitem ou impedem a 
transferência de práticas entre fronteiras. Brannen et al. (1998) pesquisaram a transferência de processos, técnicas e procedimentos formais, padronizados, da NSK no Japão para sua fábrica nos Estados Unidos durante mais de uma década. Os autores descobriram que algumas práticas passaram por recontextualização, enquanto outras mantiveram as características da matriz. A conclusão deles foi de que as práticas relacionadas a processos sociais - disciplina e formação de grupos no chão-defábrica, papéis no trabal ho e ciclos de qualidade - foram aquelas que passaram por maior recontextualização. A tendência à transformação de uma determinada prática é uma função do grau de envolvimento com o sistema e da quantidade de conhecimento tácito requerido. Fruin (1998) comparou o desenvolvimento de duas fábricas da Toshiba - uma nos Estados U nidos e outra na França - durante os anos 1980 e começo dos anos 1990. Em todos os casos houve um prolongado atraso entre a aquisição inicial da subsidiária e o tempo em que esta começou a ter um bom desempenho - de acordo com o autor, isso representa o tempo necessário para experimentação e aprendizado na fábrica, para desenvolver as práticas genéricas e específicas, e para encorajar as abordagens específicas à empresa. Olhando para o papel específico dos supervisores expatriados no processo de transferência, Peterson et al. (1998) concluem que os estereótipos nacionais podem afetar substancial mente as relações entre supervisores e subordinados. A natureza específica desse efeito é de difícil previsão em casos específicos (Peterson et al., 1998).

Esses estudos contrastam com aqueles discutidos anteriormente, em que o foco era nas organizações de origem, pois trazem o foco para as organizações receptoras e concentram foco nos processos de apoio à transferência de práticas. Com isso, eles oferecem importantes lições para a análise da transferência entre diferentes culturas. M ais importante, el es trazem uma abordagem teórica um pouco diferente para a análise do processo de transferência, prestando mais atenção ao contexto social específico em que o conhecimento e as práticas estão sen do colocados em prática. No caso específico analisado neste artigo, essa abordagem, baseada em construção social do conhecimento, sugere que os padrões de ação devem ser reinterpretados na fábrica receptora (Westney, 1998). De acordo com essa perspectiva, "recriação" é a melhor palavra para descrever o processo de transferência.

Este artigo soma-se aos estudos de transferência de conhecimento de duas formas: primeiro, ao trazer uma visão micro do processo de transferência de conhecimen- to e, segundo, ao mostrar a interação entre a transferência e a criação de conhecimento - processos considerados chave para o entendimento da regionalização das rotinas e práticas e que devem ser gerenciadas quando as empresas estão transferindo práticas entre suas subsidiária.

\section{CENÁRIO DE PESQUISA E METODOLOGIA}

Dados os elementos tácito e social intrínsecos aos processos de transferência de conhecimento discutidos na seção anterior, uma das formas mais apropriadas de se estudar seu desenvolvimento em um ambiente organizacional é por meio de um processo longitudinal de observação em profundidade, no qual o pesquisador fica imerso no contexto cultural específico. A etnografia satisfaz bem essa proposta, permitindo a observação de padrões emergentes de interação e práticas organizacionais.

Este artigo apresenta os dados coletados em um ano de etnografia no período inicial de vida de uma fábrica. 0 objetivo geral da pesquisa foi conceituar a evolução inicial das rotinas e habilidades organizacionais. 0 ambiente escolhido foi uma nova fábrica automotiva. Ela foi a primeira que a matriz construía naquele país; a maioria dos funcionários não possuía experiência anterior no setor automotivo e muitos não tinham sequer experiência em um ambiente de produção, uma vez que a fábrica foi instalada em uma área sem tradição industrial. N essas condições, era esperada uma considerável transferência de conhecimento formal da matriz para a nova fábrica no início de suas operações. A observação desse período inicial de vida da fábrica oferece uma grande oportunidade para se entender como - e em que extensão - o conhecimento é transferido da matriz para uma nova unidade.

Fiquei em média quatro dias por semana na fábrica por um período de um ano. 0 tempo total no campo foi de aproximadamente 2 mil horas. Antes do período passado no ambiente específico, realizei uma série de 45 entrevistas em três empresas. Em seguida, escolhi uma das empresas, fiz algumas outras entrevistas em sua matriz e iniciei o estudo etnográfico na nova fábrica. Passei cerca de $60 \%$ do tempo fazendo observações - a maioria no chão-de-fábrica - e os outros $40 \%$ seguindo reuniões gerenciais e realizando entrevistas formais e informais. Minhas anotações somam 4 mil páginas de bloco de notas. Elas englobam fatos - por exemplo, quem fazia 0 quê e quando -, interpretações - espontâneas ou reações induzidas das pessoas a eventos específicos -, transcri- 
ções de reuniões, entrevistas formais e informais, e minhas próprias reações aos eventos que testemunhava. Coletei também documentos da empresa e dados de desempenho - produção e qualidade.

Durante o período de coleta de dados, escrevi muitas observações conceituais em minhas anotações. Assim que terminei o estudo, comecei o processo de interpretação dos dados. Esse processo seguiu a codificação similar ao processo de grounded theory building (Glaser e Strauss, 1967), porém mais atenção foi dada ao contexto - a grounded theory é mais focada em conceitos, a despeito dos contextos específicos, que são o centro dos estudos etnográficos. Primeiro escrevi crônicas que descreviam a evolução da fábrica sob as diversas perspectives que adotei - chão-de-fábrica, gestão de operações e área de recursos humanos. Essas crônicas tornaram-se 250 páginas que foram, por sua vez, as bases de meu desenvolvimento conceitual. Em seguida, comecei uma codificação bastante geral em busca de padrões naqueles dados, eduas categorias iniciais emergi ram: "replicação" e "adaptação". Comecei então a codificar os dados com base nessas duas categorias amplas. Desenvolvi um modelo inicial e voltei-me então para uma codificação mais específica, focada nos mecanismos por trás desses dois processos gerais, enquanto fazia uma nova revisão da literatura. Para este artigo, a principal questão foi ligar a literatura com as duas principais categorias observadas replicação e recriação. A melhor explicação que pude encontrar foi por meio do uso do conceito de conhecimento arquitetural, que tem sido desenvolvido na literatura de inovação. Assim, codifiquei meus dados com base nesse conceito, e o resultado é apresentado neste artigo.

\section{PROCESSO DE TRANSFERÊNCIA E DESENVOLVIMENTO DE CONHECIMENTO}

\begin{abstract}
"Queremos que esta fábrica seja gerenciada por funcionários locais. Ensinaremos a el es como fazemos as coisas, nós os treinaremos, os aval iaremos e sairemos daqui assim que sentirmos que não precisam mais de nossa presença [...] A fábrica será gerida por funcionários locais, mas o conhecimento e a cultura são os da empresa - queremos que essa fábrica seja igual a todas as outras que temos" - gerente geral da fábrica, entrevista oito meses antes do início da produção de carros.
\end{abstract}

A afirmação acima dá uma boa idéia de como a empresa pretendia transferir seu conhecimento para a nova sub- sidiária. Queriam transferir o mais rápida e extensivamente possível. Mais do que as práticas específicas das outras fábricas, os expatriados queriam transferir seu jeito de fazer as coisas. Para atingir isso, planejaram o processo de aprendizado cuidadosamente. A maioria dos funcionários não tinha experiência anterior em empresas automobilísticas, então eles passaram por um treinamento extensivo antes de começar a trabal har na fábrica. Mais de $80 \%$ dos gerentes passaram al gumas semanas em uma filial no exterior para aprender com seus colegas.

0 processo de transferência de conhecimento pode ser dividido em dois estágios distintos. Primeiro, um período inicial em que o aprendizado se deu mais localmente e foi caracterizado pela transferência por meio de documentos, treinamento e trabal ho de expatriados. Essa fase durou até o início das atividades produtivas. Desse ponto em diante, o processo mudou drasticamente: os documentos e a intervenção dos expatriados não eram mais suficientes para resolver os muitos problemas que surgiam; a maioria desses problemas requeria alguma forma de aprendizado compartilhado que não tinha ocorrido até aquele ponto. Como resposta a esses problemas, os funcionários desenvolveram processos coletivos de compartilhamento de entendimentos, o que permitiu que el es começassem a desenvolver conhecimento arquitetural localmente. As seções seguintes detal harão essas duas fases.

\section{Estágio inicial: transferindo conhecimento dos componentes}

0 aprendizado inicial ocorreu no interior das áreas. Os novos membros da organização tiveram de ler os procedimentos da empresa, e foi-Ihes ensinado pelos expatriados como executar suas tarefas. Como os carros ainda não estavam sendo fabricados nesse momento, as atividades do dia-a-dia consistiam, em sua maioria, no planejamento e na preparação para a fase produtiva. Nesse estágio as áreas estavam desenvolvendo, principalmente, conhecimento dos componentes, em oposição a conhecimento arquitetural. Os funcionários estavam aprendendo os conceitos principais para exercerem as atividades específicas em suas áreas, mas ainda não tinham nenhuma idéia de como o sistema como um todo iria funcionar quando a produção começasse. As interdependências ainda eram poucas. Assim, as áreas viviam praticamente isoladas. Por exemplo, os funcionários do planejamento da produção aprenderam a usar o software específico da empresa, as regras que deveriam ser seguidas quando da programação da produção, a estrutura de sua área e como interagir com seus colegas. As pessoas que trabal havam na área de suprimen- 
tos desenvolveram relacionamentos com os fornecedores, aprenderam sobre as opções de transporte, leis aduaneiras, logística interna e externa.

Essa transferência inicial de conhecimento dos componentes correu sem grandes problemas até o ponto em que a produção começou. Conforme os funcionários das diferentes áreas começaram a interagir e os novos fluxos de material e informação foram desenvolvidos, eles enfrentaram diversas barreiras que atrasaram o desenvolvimento da produção. Os funcionários haviam aprendido o papel que eles deveriam desenvolver na organização pelos documentos da empresa, mas agir daquela forma provou-se muito mais difícil do que o esperado. Era difícil encontrar a informação correta, as decisões eram constantemente adiadas e os problemas eram complexos demais para serem resolvidos rapidamente. Por exemplo, no primeiro mês de produção o número de carros com defeito foi muito maior que o esperado. E a identificação e a solução dos problemas acerca dos defeitos foram muito difíceis, pois não havia rotinas organizacionais para executar essas ações. Antes de resolver os problemas em si, os funcionários tiveram de aprender como resolver problemas. Em face desses desafios, os membros da empresa começaram a desenvolver o conhecimento arquitetural necessário para colocar em prática o conhecimento individual que haviam acumulado na fase inicial.

\section{Ultrapassando a barreira da ação: desenvolvendo conhecimento arquitetural localmente}

\begin{abstract}
"Os gerentes de linha têm tudo o que precisam para realizar suas tarefas. Eles são engenheiros, passaram por treinamento exaustivo, sabem os procedimentos da empresa e o que é esperado de sua função - apesar disso, el es não estão tomando nenhuma iniciativa, el es estão muito aquém do que esperamos de um gerente de linha" - diretor industrial, entrevista realizada sete meses após o início da produção.
\end{abstract}

"Eles esperam que eu tome iniciativas - mas como? As coisas estão bastante confusas. Eu dependo de tantas áreas... N inguém sabe exatamente o que fazer, os pedidos vêm e vão, tudo é tão ambíguo... Olhe aqui, esses procedimentos não dizem nada sobre como devo me relacionar com a área que planeja a entrega de peças. 0 que posso fazer se preciso deles para alterar os procedimentos de entrega?" - gerente de linha, conversa informal sete meses após o início da produção.
Quando a produção começou, os problemas aumentaram exponencial mente. Esses problemas envolviam muitas áreas ao mesmo tempo, e o conhecimento individual de cada área não era suficiente para resolvêlos. A maioria dos desafios estava relacionada a questões de identificação e solução de problemas. Os funcionários locais não tinham idéia clara das ligações entre as áreas e o papel de cada área especificamente, então eles lançaram mão do comportamento de evitar problemas, colocando culpa em outras áreas. Existiam brigas constantes entre a área de produção e a de aquisição de peças - a falta de componentes era um problema comum no período inicial e nenhuma das áreas queria se responsabilizar por isso. Os expatriados ajudaram na definição de responsabilidades, mas algumas questões eram ambíguas até mesmo para eles, além de eles serem poucos para ajudar em todos os problemas que aconteciam naquele momento.

0 que fal tava naquele estágio era o conhecimento arquitetural que informaria como todos os vários pedaços de conhecimento individual deveriam ser unidos; por exemplo, o conhecimento acerca do planejamento da compra de peças, dados os problemas de qualidade no fluxo diário da produção - um tipo de conhecimento arquitetural que demandou uma integração do conhecimento dos componentes das áreas de produção, de qualidade e de compras.

Os membros da organização começaram a desenvolver esse conhecimento para responder a seus problemas crescentes. As reuniões eram o mecanismo mais importante para a gestão diária da produção e elas também se tornaram o principal fórum para o desenvolvimento de conhecimento arquitetural por meio das interações. Isso não foi idealizado desta forma: o gerente industrial reclamava constantemente que as reuniões eram demoradas e divergiam muito do formato esperado. De acordo com os planos da empresa, a reunião diária de produção deveria ser um pequeno resumo das questões principais e dos problemas que a produção enfrentaria naquele dia; os problemas deveriam ser resolvidos no contato direto entre as áreas ou em reuniões específicas - como as reuniões bissemanais, que discutiam irregularidades na qualidade. Entretanto, não aconteceu dessa forma. $\mathrm{N}$ as reuniões específicas nunca estavam presentes todos que deveriam estar - as pessoas preferiam investir seu tempo em prolongadas reuniões diárias de produção. Muitos funcionários mencionaram a mim que gostavam de saber o que estava acontecendo na montagem como um todo, por isso freqüentavam as reuniões gerais - embora muitos também as achassem muito longas. Dada a ambigüidade a respeito de papéis e ações, as pessoas sentiram 
necessidade de estar todos juntos diariamente para discutir os problemas mais cruciais como um grupo. Dessa forma, as reuniões tornaram-se um passo necessário na solução de problemas, pois elas reduziam as ambigüidades e ajudavam os membros a decidirem o curso das ações de forma mais consensual. Os funcionários precisavam compartilhar conhecimento e interpretar os eventos conjuntamente, e as reuniões eram o fórum ideal para isso.

Dentro dessa resposta adaptativa mais geral - fazer uma reunião - existia uma série de mecanismos de contextualização que ajudaram os membros locais a aprenderem suas tarefas e aplicarem seu conhecimento na solução de problemas. 0 primeiro mecanismo que surgiu foi o brainstorming. Dadas as ambigüidades nos papéis e no escopo de cada área, as discussões sobre os problemas na produção geralmente envolviam uma troca rica entre os membros. Cada um fornecia informações sobre os processos internos de sua área, assim os membros de outras áreas podiam aprender o escopo e o papel de cada uma no todo. Por meio dessas trocas, a memória transacional começou a ser desenvolvida.

A memória transacional é definida como um sistema compartilhado de codificação, armazenamento e recuperação de informação, e começa quando as pessoas aprendem algo sobre o domínio de conhecimento do outro (Wegner, 1986). Traz benefícios importantes para a performance de um grupo, incluindo melhor coordenação de tarefas, melhor planejamento de trabal ho e mais fácil e rápida resolução de problemas (M oreland, 1999).

0 processo ocorreu de forma lenta pois os membros que participavam das reuniões mudavam freqüentemente - as áreas mandavam diferentes representantes - e porque havia ambigüidades internas nas próprias áreas que tiveram de ser resolvidas - muitos representantes de equipes não sabiam ao certo o escopo das atividades de suas próprias áreas.

Nos primeiros meses, quando o conhecimento dos componentes estava sendo desenvolvido, os expatriados tinham um papel maior na redução de ambigüidades, fornecendo direções e explicações. Mas durante as reuniões diárias de produção esse papel não era preenchido por nenhum membro em particular. Quando participavam das reuniões, os expatriados ajudavam a reduzir as ambigüidades fornecendo exemplos baseados em suas experiências anteriores na empresa, mas poucos expatriados freqüentavam essas reuniões e nunca de forma regular. Com o passar do tempo, os expatriados ficaram muito mais focados em checar conformidade. Sempre que um expatriado participava de uma reunião, se havia um problema não resolvido ele começava questionar os funcionários locais sobre cada procedimento adotado para checar se tudo havia sido feito conforme o esperado pela matriz. Na maioria das interações entre expatriados e locais durante os últimos meses, as maneiras de resolver os problemas diferiam extremamente: enquanto os primeiros queriam soluções "legítimas" - aquel as que seguiam os princípios institucionais -, os últimos procuravam por respostas "funcionais" - soluções vindas de ações que resolveriam o problema da maneira mais eficiente, mesmo que isso fosse contra o domínio institucional. Existem repetidos exemplos de duas áreas que resolveram problemas locais e foram reprimidas posteriormente, pois não haviam envolvido um engenheiro ou al guma outra área que deveria certificar a solução encontrada.

Sem muitos expatriados para fornecer orientações, a evolução das reuniões dependia da liderança dos gerentes locais e da dinâmica entre os representantes de área. Conforme os problemas no chão-de-fábrica aumentavam e a ambigüidade a respeito de papéis específicos ainda era al ta, al guns conflitos entre as áreas começaram a surgir. Durante as reuniões, quando um problema específico estava em discussão, a reação comum dos representantes de área era evitar o problema e colocar a culpa em al guma outra área. I sso geral mente gerava longas discussões, nas quais os membros buscavam as fontes dos problemas, de forma a identificar a área "culpada", e então decidiam como proceder - que documentos utilizar, ações que deveriam ser tomadas e prazos. As soluções em geral representavam um compromisso entre as diferentes áreas envolvidas com o problema, muitas vezes resultando em uma negociação explícita para determinar quem seria responsável pelo quê. 0 gerente da área conseguiu criar um ambiente de ajuda mútua, que reduziu esse tipo de conflito ao mínimo. Sua principal abordagem para conseguir esse tom colaborativo era "ser um deles"; sempre fazia referência a problemas que ele tinha mas que estavam fora de seu controle, mostrava solidariedade quando as pessoas reclamavam sobre os problemas de suas áreas e tentava criar um espírito de "somos todos produção" entre os participantes da reunião. Ele também compartilhava muitos comentários e piadas que eram feitas sobre os expatriados, deixando claro que não pertencia àquele grupo. Dessa forma, ele tentou desenvolver uma série de valores que todos compartilhassem - valores relacionados a ser parte da área de montagem em uma fábrica local - , de forma a atingir os objetivos organizacionais. 0 processo estava em conformidade com a construção de crenças locais, não com padrões recebidos da matriz, embora mecanismos como 
estrutura organizacional, artefatos e documentos obviamente criassem barreiras a esse desenvolvimento local.

Conforme os membros interagiam, as conexões entre as áreas eram criadas. Às vezes essas ligações iniciais refletiam mais as relações pessoais do que as de interdependência entre áreas - por exemplo, alguns projetos conjuntos que um engenheiro e um técnico de qualidade propuseram de forma autônoma foram consequência de seu bom relacionamento pessoal e esses projetos tiveram um efeito importante: a aproximação entre a qualidade e a engenharia de processo. As interdependências tiveram obviamente seu papel nas conexões desenvolvidas, uma vez que áreas que dependiam umas das outras precisavam conversar e interagir independentemente dos membros simpatizarem uns com os outros. Mas mais ações independentes surgiram do bom relacionamento pessoal. Essas conexões ajudaram as pessoas a construírem conhecimentos compartilhados, em um primeiro momento acerca de questões simples, como o quefazer quando encontram um problema ou como preencher um formulário. No final do meu período na fábrica, os problemas eram bem mais complexos, requisitando a participação de três ou quatro áreas e mais esforços para construir entendimentos compartilhados.

Uma outra característica importante do processo de recriação era o número de documentos e procedimentos que eram criados pelos participantes das reuniões. Os documentos foram criados usualmente para medir o desenvolvimento de questões importantes na fase inicial por exemplo, relatórios sobre a evolução do estoque de peças ou gráficos que controlavam a melhoria da qualidade e as resoluções de problemas que aconteciam. Esses documentos serviram para reduzir al gumas das ambigüidades dos primeiros dias, uma vez que trouxeram formas de medir desempenho em um ambiente em que as pessoas não sabiam se seus esforços estavam resultando em melhorias ou não. No que diz respeito aos procedimentos, muitas atividades entre áreas que não estavam especificadas nos documentos foram desenhadas e discutidas durante as reuniões - por exemplo, procedimentos de entrega de partes na linha de montagem foram criados e em seguida aprovados pelas áreas durante a reunião. Alguns desses procedimentos foram mais tarde codificados em documentos, outros permaneceram como acordos entre duas ou mais áreas e eram constantemente relembrados durante as reuniões - geral mente al go como "lembra do que combinamos na semana passada? Sua área vai nos mandar o relatório às $7 \mathrm{~h} 30 "$.

Em resumo, uma série de mecanismos emergiu da interação entre as áreas como uma resposta à ambigüidade acerca de suas práticas, entre elas, brainstorming, negociações, elaboração de documentos e procedimentos, todas levando ao estabel ecimento de conexões entreas áreas para o desenvolvimento de entendimentos compartilhados que guiassem as ações. Essas conexões e esses entendimentos compartilhados que emergiram das interações formaram o conhecimento arquitetural que era necessário para coordenar as ações. Tais processos permitiram aos membros desenvolver conhecimento sobre as formas pelas quais os componentes eram integrados, formando um todo coerente.

Mais do que criar ligações entre as diversas bases de conhecimento, a formação do conhecimento arquitetural também permitiu uma adaptação crescente das práticas ao contexto local. As ligações criadas entre as diversas bases de conhecimento refletiram a estrutura emergente da organização local e as relações específicas que se desenvolveram durante o período inicial. As forças ambientais, que eram diferentes daquelas enfrentadas pela matriz, também foram utilizadas para influenciar esse conhecimento arquitetural emergente. Conforme os trabalhadores aprendiam a unir as partes, eles também aprendiam como redesenhar essas mesmas partes para aumentar a eficiência. M uitas das adaptações locais aconteceram durante esse período. Os processos de transferência de conhecimento tornaram-se cada vez menos importantes, abrindo caminho para a recontextualização do conhecimento e para processos de criação de conhecimento. Durante esses processos, a fábrica adaptou suas práticas às condições específicas do ambiente em que estava local izada.

\section{DISCUSSÃO}

0 estudo mostra a ten são entre a replicação e o desenvolvimento local de conhecimento no processo de transferência de práticas. Enquanto o conhecimento dos componentes foi codificado e transferido com relativa facilidade, o conhecimento arquitetural teve de ser desenvolvido localmente. 0 processo de formação de conhecimento arquitetural é conceitual mente equivalente à espiral de criação de conhecimento de Nonaka (1994), em que o conhecimento tácito trazido pelos indivíduos é dividido com outros membros por meio da socialização e, em seguida, tornado explícito por externalização, para então ser combinado a outros conhecimentos explícitos e, finalmente, ser internalizado de forma tácita - e o processo começa novamente. N esse processo, o conhecimento é criado 
por meio das interações entre pessoas com diferentes tipos e conteúdos de conhecimento (Nonaka et al., 2000)

No caso particular aqui analisado, ao invés de acontecer no nível individual, a espiral de conhecimento ocorreu no nível da área: as áreas externalizavam seus conhecimentos durante as reuniões, combinavam-nos com os vindos de outras áreas e, por fim, internal izavam o novo conhecimento combinado em suas práticas. As pessoas eram os agentes do processo, mas olhar para o nível da área pode oferecer importantes insights sobre a dinâmica da criação de conhecimento organizacional, especialmente sobre a interação entre diferentes grupos. Os indivíduos estavam representando suas áreas e agiam em nome delas durante as reuniões. 0 aprendizado era compartiIhado com as outras áreas em seguida; as rotinas desenvolvidas ligavam as áreas, não as pessoas. Dessa forma, mais aspectos coletivos do conhecimento arquitetural puderam ser desenvolvidos durante esse processo.

0 estudo mostra a importância de se construir conhecimento arquitetural na transferência de práticas para outro local de produção. Mas uma questão importante que merece ser mencionada é: por que o conhecimento arquitetural falhou no início? 0 treinamento inicial da força de trabal ho nas fábricas internacionais buscava criar um pouco desse conhecimento, mas não atingiu seu objetivo por al gumas razões. A primeira está relacionada à natureza do próprio conhecimento: o conhecimento individual émais particular eexplícito, enquanto o conhecimento arquitetural é mais coletivo etácito. A literatura mostrou as dificul dades na transferência de conhecimento tácito para conhecimento coletivo e as vantagens competitivas que essas dificuldades trazem às empresas em termos de não-imitabilidade (Kogut e Zander, 1992; Grant, 1996; Spender, 1996).

Outra dificuldade encontrada na transferência referese ao momento em que o conhecimento arquitetural foi ensinado aos novos funcionários. A maioria deles passou algum tempo no exterior logo depois de terem sido contratados. Alguns me disseram em uma entrevista feita durante o período de treinamento no exterior:

“Estamos aprendendo 10\% daquilo que eles nos falam... Há uma barreira de idioma, mas, principalmente, a organização é complexa demais... Acabamos de ser contratados, não sabemos como as coisas funcionam na organização e eles querem que aprendamos tudo aqui... Mas as pessoas daqui assumem que sabemos como a empresa funciona, eles estão aqui há anos e não percebem como é difícil para um novo funcionário entender tudo... Existem também tantas áreas diferentes, qual é o papel exato de cada uma?".

Essa afirmação, confirmada posteriormente por muitas pessoas com as quais interagi na fábrica sugere que, para absorver conhecimento arquitetural, os receptores devem possuir um certo nível de conhecimento dos componentes. Se eles tivessem sido enviados para o exterior depois de ter trabal hado algum tempo na nova fábrica, teriam sido capazes de focar mais o aprendizado, absorvendo mais facilmente o conhecimento arquitetural necessário para realizar suas atividades.

A terceira razão está relacionada às escolhas gerenciais da matriz. Elas estavam focadas na transferência de conhecimento dos componentes, sem que a importância do conhecimento arquitetural fosse notada. Foi decidida a transferência dos grupos de "melhores práticas" de diferentes fábricas de forma que a nova fábrica refletisse os processos produtivos e o conhecimento gerencial mais avançados. Assumiu-se que colocar essas partes juntas seria uma tarefa descomplicada. Quando se percebeu a dificuldade de se fazerem as ligações, era muito tarde para estruturar o processo de transferência - o conhecimento arquitetural teve de ser criado localmente.

A última razão diz respeito à dificuldade inerente de se transferir conhecimento arquitetural. Esse tipo de conhecimento é tácito e altamente impregnado em relações sociais específicas, refletindo tanto a cultura da empresa quanto 0 ambiente institucional em que el a está inserida. Assim, al guma regional ização desse conhecimento se faz necessária: a transferência de conhecimento tem de ser complementada com algum conhecimento específico criado localmente. Isso é consistente com os estudos de Fruin (1998) e Brannen et al. (1998) acerca da transferência de práticas.

Como sugerido por Peterson et al. (1998), os expatriados tiveram um importante papel na transferência de conhecimento durante a fase inicial. $\mathrm{Na}$ fase de transferência de conhecimento individual, atuaram como professores e mentores para os empregados locais. No entanto, durante 0 desenvolvimento de conhecimento arquitetural, estavam também aprendendo como integrar as diversas partes de conhecimento vindas de diferentes fábricas. Seu papel tornou-se mais geral, na maioria do tempo estabelecendo fronteiras para aquilo que estava sendo desenvolvido. Com base em suas experiências na organização, os expatriados impunham limites - por exemplo, "isso não pode ser feito assim", ou "isso deve ser mudado para ficar de acordo com nossas políticas" - 
e estabeleciam prioridades - por exemplo, "precisamos resolver esse problema primeiro". Eles eram faróis iluminando o caminho que deveria ser seguido pelos membros locais. Quando a regionalização do conhecimento começou, seu papel voltou a ser ativo. Inicialmente, foram resistentes a quaisquer tentativas de mudança das práticas da empresa, mas, conforme a confiança nos funcionários locais foi aumentando, eles deram mais liberdade para as mudanças, garantindo apenas que toda mudança estivesse de acordo com a maneira da empresa fazer as coisas.

\section{IMPLICAÇÕES}

"Um de nossos erros anteriores foi tentar combinar em nossa fábrica aqui o melhor de nossas diversas fábricas. Cada uma contribuiu um pouco, mas no final ninguém sabia como o todo funcionava - os expatriados estavam tão acostumados com seus próprios sistemas que foi difícil trabalhar sob essa nova lógica. Os padrões de interação eram diferentes, era muito complexo unir todas as partes" - diretor industrial, entrevista realizada 11 meses após o início das operações da nova fábrica.

0 caso mostrou que a principal barrei ra para a transferência de bases de conhecimento complexas e diversas para uma nova fábrica foi a falha na transferência de conhecimento arquitetural. Sem ele, foi difícil para os receptores compreenderem como as diferentes bases de conhecimento transferidas se encaixavam. A partir disso, existem algumas implicações para os gestores que planejam processos de transferência de conhecimento de processos.

A primeira implicação diz respeito à escolha das fontes de transferência de conhecimento. A frase mencionada anteriormente sugere que a transferência de um grupo de "melhores práticas" individuais de muitas fontes diferentes é muito arriscada. Cada prática será tirada de seu contexto original e separada de seu conhecimento arquitetural intrínseco. Assim, o conhecimento arquitetural deverá ser reconstruído praticamente do zero no ambiente receptor, e mesmo executivos experientes podem encontrar dificuldades em gerenciar esse processo. Expatriados trarão estruturas cognitivas e de comportamento de seus locais de origem e podem achar difícil a adaptação à nova situação, que requer ligações um tanto distintas entre as bases de conhecimento em relação àquelas com as quais eles estão acostumados.
A transferência de um grupo completo de práticas de uma fonte específica é uma escolha mais adequada. 0 conhecimento arquitetural virá embutido nesse conjunto e o papel dos expatriados na transferência torna-se mais fácil. Ao invés de ter de aprender uma nova forma de se fazerem as coisas, eles podem concentrar esforços em dividir seus conhecimentos tácitos e explícitos com os funcionários locais. Essa implicação de meu estudo é consistente com a hipótese de Winter e Szulanski (2001), de que a replicação é mais efetiva quanto segue um modelo - definido como um exemplo de trabal ho - e quando se baseia no esforço inicial de copiar o modelo precisamente. Mas meu estudo também sugere que a transferência precisa de um modelo não é suficiente. Na maioria dos casos, o conhecimento arquitetural precisará passar por processos de recontextualização que tragam as características sociais e institucionais do novo cenário. Essa recontextualização é mais importante quando esse novo cenário situa-se em um ambiente geográfico e cultural diferente do da fonte. Os gestores precisam manter o equilíbrio entre a necessidade de seguir precisamente o modelo e a necessidade de adaptá-lo às características locais - o que aumenta a eficácia e eficiência da transferência de conhecimento.

Outra implicação concerne ao momento de transferência dos diferentes conhecimentos dos componentes. 0 conhecimento arquitetural parece ser bastante difícil de ser transferido se os receptores não tiverem atingido um certo nível de conhecimento individual. Mas o conhecimento dos componentes precisa de algum nível de conhecimento arquitetural para ser colocado em prática. A seqüência mais plausível para se superar esse problema é começar com a transferência formal de conhecimento dos componentes, para em seguida transferir conhecimento arquitetural e, finalmente, criar mais flexibilidade nos processos para acomodar a recontextual ização e a regionalização do conhecimento.

Embora o processo descrito aqui venha de um caso específico do setor manufatureiro, pode gerar insights para uma ampla gama de ocorrências de transferência e desenvolvimento de conhecimento. 0 aumento do uso da lógica modular em gerenciamento de projetos (Baldwin e Clark, 1997) amplia a importância do desenvolvimento do conhecimento arquitetural. Correntes teóricas na área de estratégia também apontam para a importância das competências integradoras, que está fortemente ligada à noção de conhecimento arquitetural (Henderson e Cockburn, 2000). Os estudos de transferência de conhecimento precisam colocar mais ênfase nesses el ementos integradores da transferência. Este ar- 
tigo é o primeiro passo na direção da compreensão desse fenômeno e dos desafios associados a ele.

\section{LIMITAÇÕES E CONCLUSÕES}

U ma limitação do estudo diz respeito às dificuldades naturais de se capturar toda a riqueza de um contexto no espaço de um artigo. Busquei trazer, aqui, os aspectos mais rel evantes que caracterizaram o processo de acordo com meu modo de análise dos dados, mas muitos detaIhes foram deixados de lado. Há também as limitações comuns a um estudo etnográfico. Os objetivos da etnografia não são os mesmos do que os de uma pesquisa quantitativa; não é possível, por exemplo, falar em replicação nesse tipo de estudo ou questionar seu potencial de generalização, pelo menos no uso corrente da palavra. M as al guns critérios de avaliação podem substituir aqueles vindos das pesquisas orientadas à estatística. Stewart (1998) propõe que, ao invés da validação, da confiabilidade e do potencial de generalização, os estudos etnográficos devam ser baseados em veracidade, objetividade e perceptividade. Veracidade significa que 0 pesquisador realmente observou o que sua descrição demonstra. A objetividade é al cançada quando o estudo transcende as perspectivas do pesquisador e de seus informantes. $E$ a perceptividade implica que a pesquisa gere lições que sejam aplicáveis em outro tempo e em outros lugares. Embora a teoria gerada pelos dados etnográficos esteja obviamente ligada ao contexto social específico em que eles foram coletados, etnógrafos podem especificar as contingências nas quais os resultados se aplicam, de modo que possam ser comparados com outros contextos e outras teorias. Este artigo representa um esforço no sentido de atingir essas três características, gerando insights a partir de dados coletados na prática, que contribuam para o entendimento de um importante tópico nos estudos organizacionais.

Assim, este artigo mostrou a importância do conhecimento arquitetural - definido como o "conhecimento sobre as formas com as quais os componentes são integrados e ligados de maneira coerente" - durante a transferência de práticas em uma empresa. Embora tenha demandado tempo e al gumas vezes tenha sido cheio de conflitos, 0 processo de construção desse conhecimento arquitetural localmente teve dois papéis importantes para a nova fábrica: 1) ajudou os empregados locais a aprenderem relações de causa e efeito e, assim, tornarem-se mais hábeis na tomada de decisão, sem a necessidade de ajuda dos expatriados; e2) promoveu espaço para adaptações locais
- por exemplo, o uso de diferentes ferramentas, algumas melhorias de processo e mudanças na logística.

As mais importantes sugestões para os gestores são: usar apenas uma fonte de conhecimento para estabelecer um novo contexto - em vez de usar "melhores práticas" vindas de diferentes locais da empresa; planejar os períodos de treinamento na matriz para os funcionários da filial receptora do conhecimento apenas após estes terem aprendido suas atividades básicas; e usar expatriados para estabelecer as fronteiras para o desenvolvimento local de conhecimento arquitetural.

Além dessas contribuições para a prática, o presente artigo soma-se à literatura de transferência de conhecimento ao promover uma análise longitudinal de um processo de transferência de conhecimento entre diferentes culturas em uma empresa. 0 foco dos estudos sobre transferência tinha sido até aqui sobre o conhecimento dos componentes. Este estudo sugere que o conhecimento arquitetural é de fundamental importância e detal ha sua evolução nas condições estudadas. Futuros estudos são necessários para que se possa começar a detal har os mecanismos por trás da transferência de conhecimento arquitetural, especial mente as contingências que determinam o grau de desenvolvimento local necessário.

\section{Artigo recebido em 15.01.2003. Aprovado em 15.10.2003. Traduzido por Tatiana Tinoco.}

\section{Nota}

0 autor agradece a orientação de Yves Doz, Quy Huy, John Van Maanen e John Weeks, os comentários de Michael Yasiji e Nicola Dragonetti e a tradução de Tatiana Tinoco. Esse estudo teve apoio financeiro do programa de doutorado do INSEAD e do GE Fund.

\section{Referências bibliográficas}

ADLER, P. S.; COLE, R. E. Designed for learning: A tale of two auto plants. Sloan Management Review, v. 34, n. 3, p. 85-94, 1993.

ARGOTE, L. Organizational learning: Creating, retaining and transferring knowledge. London: Kluwer Academic, 1999.

BALDWIN, C.; CLARK, K. B. Managing in an age of modularity. Harvard Business Review, v. 75, n. 5, p. 84-93, 1997.

BAUM, J. A.; INGRAM, P. Survival-enhancing learning in the Manhattan hotel industry. Management Science, v. 44, n. 7, p. 996-1016, 1998.

BRANNEN, M. Y.; LIKER, J. K.; FRUIN, W. M. Recontextualization and factory-to-factory knowledge transfer from Japan to the US: The case of NSK. In: LIKER, J. K.; FRUIN, W. M.; ADLER, P. S. (eeds.). Remade in America: Transplanting and transforming Japanese management systems. Oxford: Oxford University Press, 1998. 


\section{PAULO PROCHNO}

COHEN, W. M.; LEVINTHAL, D. A. Absorptive capacity: A new perspective on learning and innovation. Administrative Science Quarterly, v. 35, n. 1, p. 128-152, 1990.

DARR, E.; ARGOTE, L.; EPPLE, D. The acquisition, transfer and depreciation of knowledge in service organizations: Productivity in franchises. Management Science, v. 41, n. 11, p. 1750-1762, 1995.

EPPLE, D.; ARGOTE, L.; MURPHY, K. An empirical investigation of the microstructure of knowledge acquisition and transfer through learning by doing. Operations Research, v. 44, n. 1, p. 77-86, 1996.

FLIGSTEIN, N. The spread of the multi divisional form among large firms, 1919-1979. American Sociological Review, v. 50, p. 377-391, 1985.

FRUIN, W. M. Site-specific organization learning in international technology transfer: Example from Toshiba. In: LIKER, J. K.; FRUIN, W. M.; ADLER, P. S. (eds.). Remade in America: Tansplanting and transforming Japanese management systems. Oxford: Oxford University Press, p.232-255, 1998.

GALBRAITH, C. S. Transfering core manufacturing technologies in high technology firms. California Management Review, v. 32, n. 4, p. 56-70, 1990.

GLASER, B.; STRAUSS, A. The discovery of grounded theory. London: Wiedenfeld and Nicholson, 1967

GRANT, R. Toward a knowledge-based theory of the firm. Strategic M anagement Journal, v. 17, Winter Special Issue, p. 109-122, 1996.

HENDERSON, R.; CLARK, K. B. Architectural innovation: The reconfiguration of existing product technologies and the failure of established firms. Administrative Science Quarterly, v. 35, n. 1, p. 9-30, 1990.

HENDERSON, R.; COCKBURN, I. Scale, scope and spillovers: The determinants of research productivity in drug discovery. The Rand Journal of Economics, v. 27, n. 1, p. 32-59, 1996.

HENDERSON, R.; COCKBURN, I. M easuring competence? Exploring firm effects in drug discovery. In: DOSI, G.; NELSON, R. R.; WINTER, S. (eds.). The nature and dynamics of organizational capabilities. Oxford: Oxford University Press, p.155-182, 2000

KOGUT, B.; ZANDER, U. Knowledge of the firm, combinative capabilities and the replication of technology. Organization Science, v. 3, n. 3, p. 383397, 1992

LIKER, J. K.; FRUIN, W. M.; ADLER, P. S. Bringing Japanese Management systems to the United States: Transplantation or transformation? In: LIKER, J. K.; FRUIN, W. M.; ADLER, P. S. (eds.). Remade in America: Transplanting and transforming Japanese management systems. Oxford: Oxford University Press, p. 3-35, 1998.

MORELAND, R. Transactive memory: Learning who knows what in work groups and organizations. In: THOMPSON, L.; LEVINE, J.; MESSICK, D. (eds.). Shared cognition in organizations. London: Lawrence Erlbaum Associates, 1999
NONAKA, I. A dynamic theory of organizational knowledge creation. Organization Science, v. 5, n. 1, p. 14-37, 1994.

NONAKA, I.; TOYAMA, R.; NAGATA, I. A firm as a knowledge-creating entity: A new perspective on the theory of the firm. Industrial and Corporate Change, v. 9, n. 1, p. 1-20, 2000.

O'DELL, C.; GRAYSON JR, C. J. If only we knew what we know. New York: The Free Press, 1998

PETERSON, M.; PENG, T.; SMITH, P. Using expatriate supervisors to promote cross-border management practice transfer. In: LIKER, J. K.; FRUIN, W. M.; ADLER, P. S. (eds.). Remade in America: Transplanting and transforming Japanese management systems. Oxford: Oxford University Press, p.294-327, 1998.

ROGERS, E. M. Difussion of innovations. London : Free Press, 1995.

ROTHWELL, R. Some problems of technology transfer into industry: Examples from the textile machinery sector. IEEE Transactions on Engineering Management, v. 25, n. 1, p. 15-20, 1978.

SPENDER, J. C. Making knowledge the basis of a dynamic theory of the firm. Strategic M anagement Journal, v. 17, Winter Special Issue, p. 45-62, 1996.

STEWART, A. The ethnographer's method. London: Sage, 1998.

SZULAN SKI, G. Exploring internal stickiness: Impediments to the transfer of best practice within the firm. Strategic M anagement Journal, v. 17, Winter Special Issue, p. 27-43, 1996.

TOLBERT, P. S.; ZUCKER, L. G. Institutional sources of change in the formal structure of organizations: The diffusion of civil service reform, 1880-1935. Administrative Science Quarterly, v. 28, n. 1, p. 22-39, 1983.

WEGNER, D. Transactive memory: A contemporary analysis of the group mind. In: MULLEN, B.; GOETHALS, G. (eds.). Theories of group behavior. New York: Springer-Verlag, p.185-205, 1986.

WESTNEY, D. E. Organization theory perspectives on the cross-border transfer of organizational patterns. In: LIKER, J. K.; FRUIN, W. M.; ADLER, P. S. (eds.). Remade in America: Transplanting and transforming Japanese Management systems. Oxford: Oxford University Press, p. 385-408. 1998.

WINTER, S. The satisficing principle in capability learning. Strategic Management Journal, v. 21, n. 10-11, p. 981-96, 2000.

WINTER, S.; SZU LAN SKI, G. Replication as Strategy. Organization Science, v. 12, n. 6, p. $730-743,2001$.

ZANDER, U.; KOGUT, B. Knowledge and the speed of the transfer and imitation of organizational capabilities: An empirical test. Organization Science, v. 6, n. 1, p. 76-92, 1995.

ZIMMERMAN, M. B. Learning effects and the commercialization of new energy technologies: The case of nuclear power. The Rand Journal of Economics, v. 13, n. 2, p. 297-310, 1982.

\section{Paulo Prochno}

Professor adjunto das Faculdades Ibmec. Interesses de pesquisa em rotinas e habilidades organizacionais, transferência de conhecimento, aprendizagem organizacional e teoria das organizações.

E-mail: paulo.prochno@ibmecri.br

Endereço: Av. Rio Branco, 108 - 17 andar, Rio de Janeiro - RJ, 20040-001. 